\title{
OCORRÊNCIA DE Setaria magna GRISEB. E S. hassleri HACK. (GRAMI- NEAE) NO SUL DO BRASIL
}

\section{Ilsi Iob Boldrini1}

\begin{abstract}
RESUMO - Foi constatada a ocorrência, no Estado do Rio Grande do Sul, de Setaria hassleri Hack, na região das Missões e de S. magna Griseb., no Litoral, sendo essa última espécie uma citação nova para o Brasil. São fornecidas descriç̋̃es dessas duas espécies, distribuição geográfica, ilustrações, bem como uma chave analítica das espécies de Setaria Beauv. ocorrentes no Estado. Palavras-chave: Setaria, Gramineae, Sistemática.
\end{abstract}

\begin{abstract}
Occurrence of Setaria magna Griseb. and S. hassleri Hack. (Gramineae) in the south of Brazil). The occurrence of Setaria hassleri Hack. in the west, and S. magna Griseb. in the sea-shore of the State of Rio Grande do Sul, was verified. The last species is a new citation for Brazil. Descriptions of these two species with geographic distribution and illustrations are provided. Analytical key for all species of Setaria Beauv. is included.

Key words: Setaria, Gramineae, Systematics.
\end{abstract}

\section{Introdução}

Setaria Beauv. é um gênero de Gramineae com cerca de 125 espécies, constituido por representantes campestres e de interior e beira de mato.

O gênero referido acima foi motivo de estudo por Boldrini (1976), onde foi constatada a presença, no Estado do Rio Grande do Sul, de 15 espécies e 2 variedades. Posteriormente, Boldrini (1978) descreveu S. barretoi como espécie nova, baseada em material sulriograndense, totalizando então 16 espécies para o Estado.

S. hassleri Hack., descrita para o Paraguai, é citada por Ekmann (1911) para a região de Misiones na Argentina.

Nicora (1968), no trabalho sobre as espécies anuais do gênero Setaria para a flora argentina, amplia a distribuição de $\mathbf{S}$. hassleri para outras províncias: Misiones, Corrientes, Santiago del Estero e Tucumán.

Smith; Wasshousen y Klein (1982) referem-se à S. hassleri para Campo Grande e Dourados no Estado do Mato Grosso do Sul, Brasil.

Hitchcock $(1920,1935)$ indica a ocorrência de S. magna Griseb. para a costa leste e sudeste dos Estados Unidos e para a América Central.

Rominger (1962) descreve a espécie acima citada e amplia sua área de distribuição nos Estados Unidos.

Nicora (1968) descreve S. magna e a menciona para as províncias do Chaco e Corrientes na Argentina.

\section{Material e Métodos}

Com a intensificação das viagens de coleta de germoplasma nativo pelo Estado do Rio Grande do Sul, especialmente em regiões pouco exploradas, às vezes em locais de difícil acesso e em épocas não tradicionalmente interessantes para esta finalidade, houve a constatação de mais duas espécies de Setaria para o Estado. O material coletado foi herborizado e incorporado ao Herbário do Departamento de Botânica da Universidade Federal do Rio Grande do Sul (ICN).

Foram revisados herbários nacionais e estrangeiros e as siglas estão de acordo com o Index herbariorum (Stafleu, F.A. 1981): BLA, ICN, PACA, PEL e o herbário particu-

${ }^{1}$ Universidade Federal do Rio Grande do Sul, Departamento de Botânica, Av. Paulo Gama n 40. Porto Alegre (RS) 90040 
lar de Karner Hagelund, Arroio dos Ratos, RS.

Foi analisado um exemplar de S. hassleri depositado no Herbário de la Universidad Nacional del Nordeste, Corrientes, Argentina (CTES) e o exemplar-tipo da mesma espécie anexado ao Herbário Gaspar Xuárez, da Faculdade de Agronomia e Veterinária de Buenos Aires, Argentina (BAA).

A identificação das espécies foi baseada nas obras de Nicora (1968) e de Hitchcock (1920) e no exemplar-tipo de S. hassleri.

\section{Resultados}

Chave para identificação das espécies de Setaria Beauv. ocorrentes no Rio Grande do Sul, Brasil.

A. Lâminas basais pecioladas. Colo densamente piloso. Plantas ciófilas ou semiciófilas, preferentemente de locais úmidos.

B. Folhas plicadas. Espiguetas com uma ou nenhuma cerda. Pálea inferior menor que antécio fértil, podendo ser atrofiada ou nula.

S. poiretiana (Schult.) Kunth

BB. Folhas lisas. Espiguetas com 1, 2 ou 3 cerdas basais. Pálea inferior do mesmo comprimento que o antécio, ou apenas um pouco menor.

S. vulpiseta (Lam.) Roem. \& Schult.

AA. Lâminas não pecioladas. Colo glabro. Plantas heliófilas.

C. Cerdas retrorsas, panícula aderente.

D. Cerdas com dentículos retrorsos em todo o comprimento. Antécio fértil com rugosidade pouco pronunciada.

S. adhaerens (Forsk.) Chiov. ${ }^{2}$

DD. Cerdas com dentículos retrorsos no terço superior ou apenas no ápice e antrorsos no restante. Antécio com rugosidade muito pronunciada.

E. Cerdas de 2,5 a 5,0 mm de comprimento. Espigueta de 1,3 a 1,6 mm. Pálea inferior $1 / 2$ do comprimento do lema inferior.

S. scandens Schrad. ex Schult.

EE. Cerdas de 0,6 a 15,0 mm de comprimento. Espigueta de 2,0 a 2,5 mm. Pálea inferior do mesmo comprimento do lema inferior.

CC. Cerdas antrorsas, panícula não aderente.

S. hassleri Hack.

F. Planta estolhosa, estolões de até $1,30 \mathrm{~m}$ de comprimento. Antécio com rugosidade somente na porção central.

S. stolonifera Boldrini

FF. Plantas cespitosas ou rizomatosas (às vezes com estolões curtos em

S. rosengurttii). Antécio com dorso totalmente liso ou rugoso.

G. Espiguetas de 1,5 a 2,0 mm de comprimento.

H. Espigueta acompanhada por 4 a 12 cerdas basais.

S. geniculata (Lam.) Beauv.

HH. Espigueta acompanhada por 1 a 3 cerdas basais.

I. Planta anual. Gluma superior cobrindo totalmente, ou quase, o antécio fértil, o qual é liso ou apresenta rugosidade tênue.

J. Planta adventícia, de 10 a $60 \mathrm{~cm}$ de altura.

Inflorescência de 2 a $10 \mathrm{~cm}$ de comprimento.

Antécio inferior neutro. Pálea inferior $1 / 4$ a $1 / 3$ da pálea superior.

S. viridis (L.) Beauv.

\footnotetext{
2 Espécie coletada no Estado de Santa Catarina
} 
JJ. Planta de banhado, de 2 a $4 \mathrm{~m}$ de altura. Inflorescência de 20 a $55 \mathrm{~cm}$ de comprimento. Antécio inferior com flor hermafrodita. Pálea inferior do mesmo comprimento da pálea.

S. magna Griseb.

II. Planta perene. Gluma superior cobrindo 3/4 do antécio fértil, o qual é pronunciadamente rugoso.

S. fiebrigii Herrm.

GG. Espiguetas maiores que $2 \mathrm{~mm}$ de comprimento.

K. Espigueta com uma cerda basal.

L. Plantas de 1,0 a 2,5 m de altura, formando touceiras robustas. Habitam locais úmidos e banhados.

M. Cerdas com pêlos longos no terço inferior. Pálea inferior ausente. Lema fértil com pêlos nas margens.

S. paucifolia (Mor.) Lindm.

MM. Cerdas glabras. Pálea inferior presente, tão longa quanto o antécio fértil. Lema fértil glabra.

N. Gluma superior 7-9-10 nervada, cobrindo 3/4 a 4/5 do antécio fértil. Espigueta verde com antécio sub-globoso, fortemente rugoso, opaco. Pálea inferior com os bordos afastados.

S. paradii Nic.

NN. Gluma superior 5-nervada, cobrindo no máximo $1 / 2$ do antécio fértil. Espigueta ocrácea com antécio ovallanceolado, debilmente rugoso, brilhante. Pálea inferior com os bordos laterais sobrepondo-se.

S. globulifera (Steud.) Griseb.

LL. Plantas de 15 a $80 \mathrm{~cm}$ de altura, semidecumbentes ou com estolões curtos. Habitam campos e terrenos baldios.

O. Espigueta lanceolada. Antécio fértil finamente rugoso. Gluma superior cobrindo $4 / 5$ do antécio fértil.

S. rosengurttii Nic.

OO. Espigueta subglobosa a globosa. Antécio fértil fortemente rugoso. Gluma superior cobre 2/3 a 3/4 do antécio fértil.

S. vaginata Spreng. KK. Espigueta com mais de uma cerda basal.

P. Espigueta com 2 a 3 cerdas basais (raramente espiguetas com uma só cerda na mesma inflorescência). Cerdas em torno de $1,5 \mathrm{~cm}$ de comprimento.

Q. Lâmina foliar com 1 a 1,5 cm de largura. Gluma superior pouco menor que o antécio fértil. Antécio fértil liso, com pálea inferior alcançando $1 / 4$ a $1 / 2$ do seu comprimento. Cultivada. S. italica (L.) Beauv.

QQ. Lâmina foliar com $0,7 \mathrm{~cm}$ de largura. Gluma superior $1 / 2$ a 2/3 do antécio fértil. Antécio fértil rugo- 
so transversalmente, com pálea inferior quase tão longa quanto o seu comprimento. Gluma superior alcançando $1 / 2$ a $2 / 3$ do antécio fértil. Nativa.

S. scabrifolia (Nees) Kunth PP. Espigueta com 4 a 14 cerdas basais. Cerdas com 0,1 a $1,2 \mathrm{~cm}$ de comprimento.

R. Colmo comprimido. Bainhas flabeladas. Inflorescência de 10 a $39 \mathrm{~cm}$ de comprimento. Altura de 70 a $180 \mathrm{~cm}$. Cultivada.

S. sphacelata Stapf \& Hubb. RR. Colmo cilíndrico. Bainhas não flabeladas. Inflorescência de 1,5 a $11,0 \mathrm{~cm}$ de comprimento. Altura de a $2080 \mathrm{~cm}$. Nativa .

S. Planta glabra, raramente pelos na base das lâminas das folhas basais. Antécio inferior masculino.

S. geniculata (Lam.) Beauv. SS. Planta vilosa, especialmente nas lâminas foliares. Antécio inferior neutro, raramente masculino.

S. barretoi Boldrini

1. Setaria hassleri Hack. Bull. Herb. Boiss. II 4:275, 1904. (Figura 1).

Planta anual 50,0 - 100,0 cm de altura, cespitosa, colmos geniculados, às vezes radicantes nos nós basais; colmos formados por 4 - 5 nós glabros, escuros; entrenós glabros, com pêlos densos próximos ao nó superior. Inovações intravaginais partem do $1^{\circ}, 2^{\circ}, 3^{\circ}$ e $4^{\circ}$ nós. Bainhas glabras, hirsutas na margem, cobrem $1 / 2$ a $2 / 3$ do entrenó; lígula membrano-pestanosa, 1,5 - 3,0 mm de compr; sendo a parte superior pestanosa maior que a parte inferior membranosa; lâminas lanceoladas, cordadas na base, agudas no ápice, 7,0 - 20,0 cm de compr. por $0,7-1,5 \mathrm{~cm}$ de larg.,escabrosas, com pêlos esparsos nas duas superfícies. Panícula espiciforme, cilíndrica, densa, 4,0 - 12,0 cm compr. por 1,0-2,0 cm larg.,incluindo as cerdas; pedúnculo com pêlos densos, de 2,0 - 3,0 mm; ráquis com pêlos rígidos, 2,0 - 3,0 mm; cerdas 0,6 $1,5 \mathrm{~cm}$ compr. antrorso-escabrosas em todo o comprimento exceto no ápice, o qual é retrorso- escabroso; espigueta globosa, arroxeada, 2,1-2,4 mm compr. por 1,3 1,4 mm larg; acompanhada por 2 a 3 cerdas basais; gluma inferior 3 - nervada, metade do comprimento do lema inferior; gluma superior 7 - nervada, cobrindo quase totalmente o antécio frutífero; lema inferior neutro, 5 - ner - 
vado, envolvendo a pálea membranácea, do mesmo comprimento da pálea fértil; lema fértil fortemente convexo, apiculado no ápice, com intensa rugosidade transversalmente, envolvendo a pálea fértil convexa, rugosa.

Habitat: solos argilosos, áreas alteradas.

Fenologia: floresce e frutifica de março a abril. Distribuição geográfica: descrita para o Paraguai, é comum na província de Misiones na Argentina (Nicora 1968), encontrada no Mato Grosso do Sul (Smith, Wasshausen y Klein 1982) e na região das Missões, Oeste do Rio Grande do Sul.

Material examinado:

BRASIL - RIO GRANDE DO SUL - Santo Ângelo, São Miguel das Missões, /IV/1985, Boldrini et alii 216 (INC 68455); Colônia Vitoria, 22/III/1971, K.Hagelund 6145 - Santo Antônio das Missões, /IV/1985 Boldrini et alii 218 (ICN 68456).

ARGENTINA - CORRIENTES, Arroyo Riachuelo y Ruta 12, 11/III/1975, C. Quarín 2982 (CTES). PARAGUAY - "In Campis Cordilhera de Altos". Hassler 3565 (BAA) - holotypus.

2. Setaria magna Griseb. Fl. Brit. West Ind. Ind. Isl. 544, 1964. (Figura 2). Chaetochloa magna (Griseb.) Scribner. U.S. Dept. Div. Agr. Bull. 4:39, 1987.

Planta anual cespitosa, 2,0 - 3,0 m de altura, com aproximadamente 10 nós escuros, sendo 3 ou 4 basais muitos próximos, dos quais surgem raízes adventícias. Entrenós glabros, ocos, 1,0 - 2,0 cm de diâmetro. Bainhas glabras, pilosas nas mafgens; lígula em forma de $\mathrm{V}$ investido, membrano-pestanosa, 1,5 - 3,0 mm de compr., sendo a parte membranosa extremamente reduzida; lâminas glabras, escabrosas, linear-lanceoladas, $50,0-70,0 \mathrm{~cm}$ de compr. por 2,0 - 3,0 cm de larg. Panícula espiciforme, densa, 30,0-50,0 cm de compr. por 3,0-5,0 cm de larg.,incluindo as cerdas; ráquis densamente pilosa; espigueta oval-lanceolada $2,1-2,4 \mathrm{~mm}$ de compr., acompanhada por 1 a 2 cerdas antrorso-escabrosas, 1,0 - 2,0 cm de compr., gluma inferior 3-5 nervada, 1,0 - 1,1 mm de compr; gluma superior 7-9 nervada, cobrindo 4/5 do antécio superior ou totalmente; lema inferior 7 - nervada, 2,0 - 2,3 $\mathrm{mm}$ de compr., envolvendo a pálea, esta do mesmo tamanho da pálea superior., antécio inferior geralmente envolvendo uma flor hermafrodita., antécio superior lanceolado, apiculado no ápice, liso, glabro, brilhante, oliváceo até castanho 1,8 - 2,1 mm de compr. por 1,0 - 1,2 mm de larg; facilmente desarticulável. Cariopse castanho-claro, de $1,3 \mathrm{~mm}$ de compr. por 1,0 $\mathrm{mm}$ de larg.

Habitat: pântanos e banhados salinos.

Fenologia: floresce e frutifica de março a abril.

Distribuição geográfica: originária da Jamaica, é freqüente na costa leste e sudeste dos Estados Unidos, vários países da América Central (Rominger 1962), na Argentina (Nicora 1968) e na costa leste do Rio Grande do Sul, na região do Litoral.

Material examinado:

BRASIL - RIO GRANDE DO SUL - Rio Grande, Taim, IV/1980, Schwarzbold (INC 68451)

- Tramandaí, 28/III/1984, Irgang et alii (ICM 68451). 


\section{Conclusões}

Com a descoberta de S. magna e S. hassleri nọ Estado do Rio Grande do Sul, modificou-se o número de espécies presentes, de 16 para 18.

S. magna, espécie adventícia, encontrada até então na Argentina, vários países da América Central e nos Estados Unidos, foi coletada na costa do Rio Grande do Sul. Provavelmente seus frutos tenham sido transportados pelas correntes marítimas até o litoral do Estado e suas sementes ali germinaram.

S. hassleri, espécie com cerdas aderentes, foi encontrada na região das Missões, sendo pouco freqüente.

\section{Referências Bibliográficas}

BOLDRINI, I.I. 1976. Gramíneas do gênero Setaria Beauv. no Rio Grande do Sul. Anu. Téc. IPZFO da Secr. Agric. do RS; Porto Alegre, 3:331-422.

BOLDRINI, I.I. 1978. Setaria barretoi spec. nov. (Gramineae). Hickenia, San Isidro, 1(21): 117-120.

EKMAN, E.L. 1911. Beiträge zur Gramineenflora von Misiones. Ark. Bot., Uppsala., 11(4):26-7.

HITCHCOCK, A.S. 1920. The North American species of Chaetochloa. Contr. U.S. natn. Herb., Washington, 22(3):155-208.

HITCHCOCK, A.S. 1935. Manual of the grasses of the United States. 2 ed. Washington, United States Department of Agriculture. p. 695-704.

NICORA, E. 1968. Las especies anuales del género Setaria de la flora argentina. Boln. Soc. argent. Bot., Buenos Aires, 12:373-82.

ROMINGER, J.M. 1962. Taxonomy of Setaria (Gramineae) in North America. Urbana, University of Illinois Press. 132p. (Illinois Biological Monographs, 29).

SMITH, L.B.; Wasshausen, D.C. \& Klein, R.M. 1981. Gramíneas. Flora Ilus. Catarinense, Itajai.

STAFLEU, F.A. 1981. Index herbariorum. Regnum veg. 106(1):1:452. 


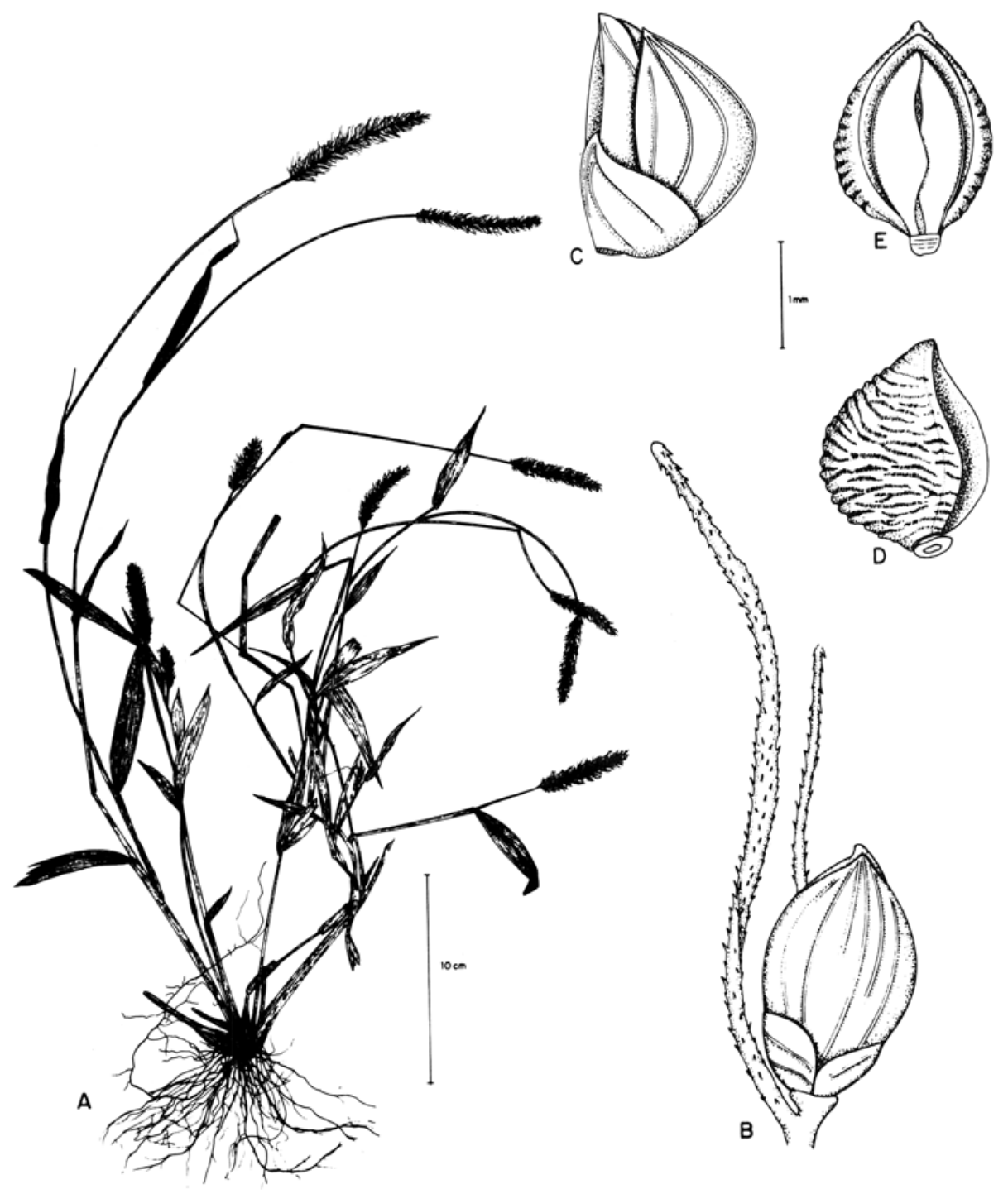

Figura 1 - Setaria hassleri Hackel: A- planta inteira, B- espigueta com cerdas, vista dorsal; C - espigueta, vista lateral; D- antécio fértil com pálea estéril; E - antécio fértil com pálea estéril, vista ventral. 


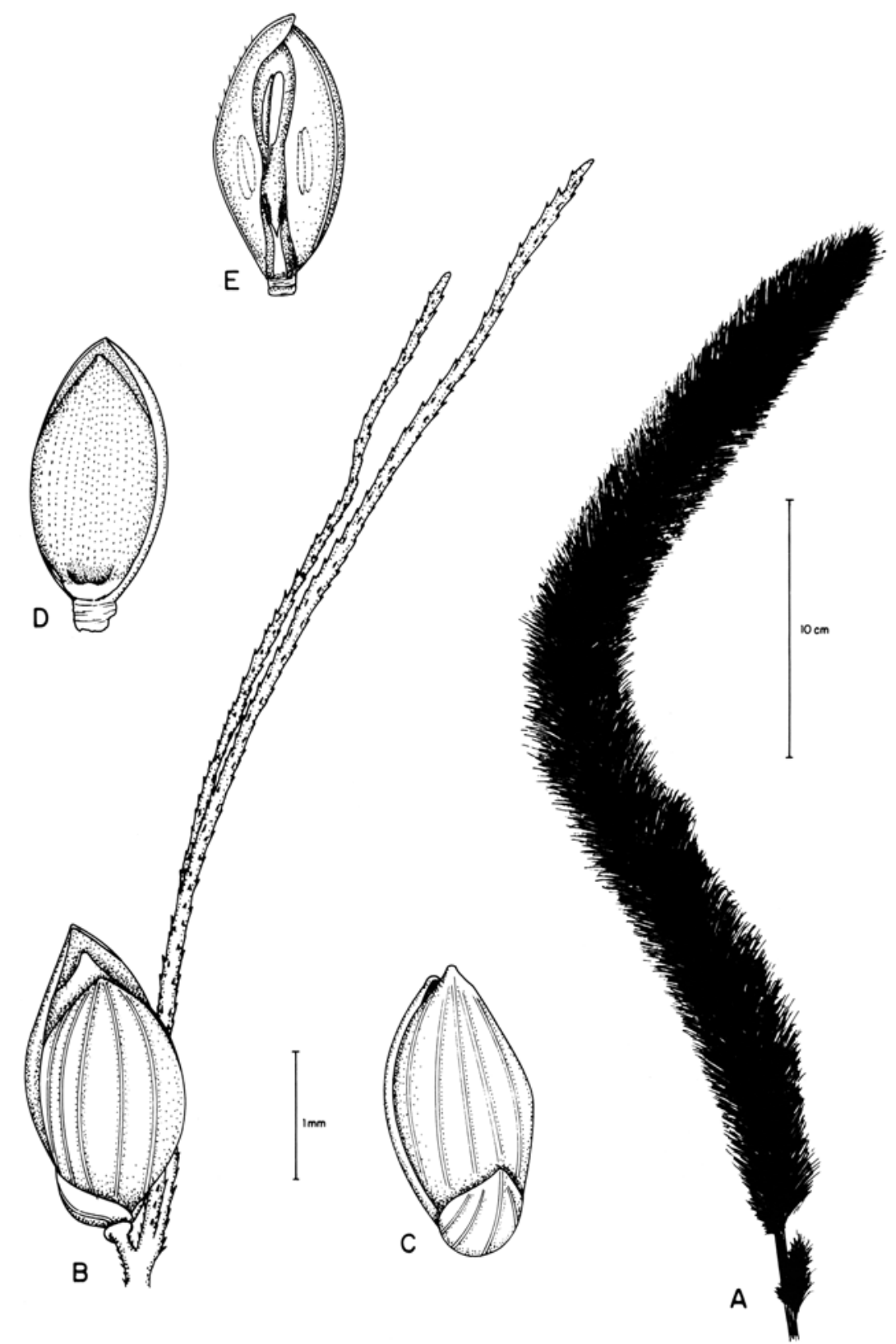

Figura 2 - Setaria magna Grisebach: A- inflorescência; B- espigueta com cerdas, vista dorsal; C- espigueta, vista ventral; D- antécio superior com lema inferior, vista dorsal; E- antécio superior com pálea inferior fértil, vista ventral. 